\title{
IDENTIFIKASI TINGKAT KESIAPSIAGAAN MASYARAKAT DESA BANJARSARI KECAMATAN GABUS TERHADAP RISIKO BENCANA BANJIR
}

\author{
Alfina Wijayanti, Khamsa'atun Salamah, Selvira Ariesta Ambarwati, Muhammad \\ Faris Abdussalam, Zulfanisa Azizah, Della Melin \\ Universitas Muhammadiyah Surakarta
}

\begin{abstract}
Abstrak : Bencana hidrometeorologi merupakan jenis bencana yang melanda wilayah Indonesia dengan tingkat kejadian tinggi, salah satunya adalah banjir. Bencana banjir biasanya terjadi akibat faktor alam dan faktor manusia. Wilayah yang memiliki tingkat risiko bencana banjir tinggi di Kabupaten Pati adalah Desa Banjarsari, Kecamatan Gabus, Kabupaten Pati. Banjir yang sering terjadi di Desa Banjarsari disebabkan oleh tingkat kepadatan penduduk yang tinggi dan letaknya berdekatan dengan sungai Silugonggo atau yang dikenal dengan Sungai Juwana. Penelitian ini bertujuan untuk mengidentifikasi tingkat pengetahuan dan kesiapsiagaan masyarakat tentang risiko bencana banjir di Desa Banjarsari, Kecamatan Gabus. Penelitian ini dilakukan menggunakan pendekatan kuantitatif dengan analisis deskriptif. Hasil dari penelitian ini menunjukkan bahwa tingkat pengetahuan dan kesiapsiagaan masyarakat Desa Banjarsari menghadapi bencana banjir sangat baik. Hal tersebut ditunjukkan dengan adanya upaya-upaya yang dilakukan masyarakat untuk menghadapi bencana banjir seperti tersedianya jalur evakuasi, tempat pengungsian, dan bangunan rumah panggung di Desa Banjarsari, Kecamatan Gabus.

Kata kunci : Bencana Banjir, Kesiapsiagaan, Desa Banjarsari
\end{abstract}

\begin{abstract}
Hydrometeorological disasters are a type of disaster that hit Indonesian areas with a high incidence, such as floods. Flood disasters usually occur due to natural factors and human factors. Areas that have a high risk of flooding in Pati Regency are Banjarsari Village, Gabus District, Pati Regency. Floods that often occur in Banjarsari Village are caused by the high level of population density and are located close to the Silugonggo River or known as the Juwana River. This research aims to identify the level of knowledge and community preparedness regarding the risk of flood disasters in Banjarsari Village, Gabus District. This research was used quantitatively with descriptive analysis. The results of this study indicate that the level of knowledge and preparedness of the Banjarsari community about flooding is very good. This is indicated by the efforts made by the community to deal with floods, such as the availability of evacuation routes, refugee camps and building houses on stilts in Banjarsari Village, Gabus District. Keywords: Flood Disaster, Preparedness, Banjarsari Village
\end{abstract}

\section{A. PENDAhuluan}

Kejadian bencana yang sering melanda wilayah Indonesia adalah kejadian bencana geologi dan bencana hidrometeorologi. Menurut Data Informasi Bencana Indonesia (DIBI)BNPB, pada Tahun 2005-2015 kejadian bencana hidrometeorologi tercatat sebanyak lebih dari 78\% (11.648) dan kejadian bencana geologi sekitar $22 \%$ (3.810) (Amri et al., 2016).

Bencana hidrometeorologi merupakan jenis bencana yang paling mendominasi dengan jumlah 
kejadiannya yaitu 2.489 (96,8\%), namun bencana geologi paling banyak menimbulkan kerusakan dan korban jiwa (BNPB, 2019). Provinsi Jawa Tengah merupakan salah satu wilayah di Indonesia yang tergolong dalam kelas bahaya sedang dan bahaya tinggi pada seluruh jenis bencana baik bencana hidrometereologi maupun bencana geologi.

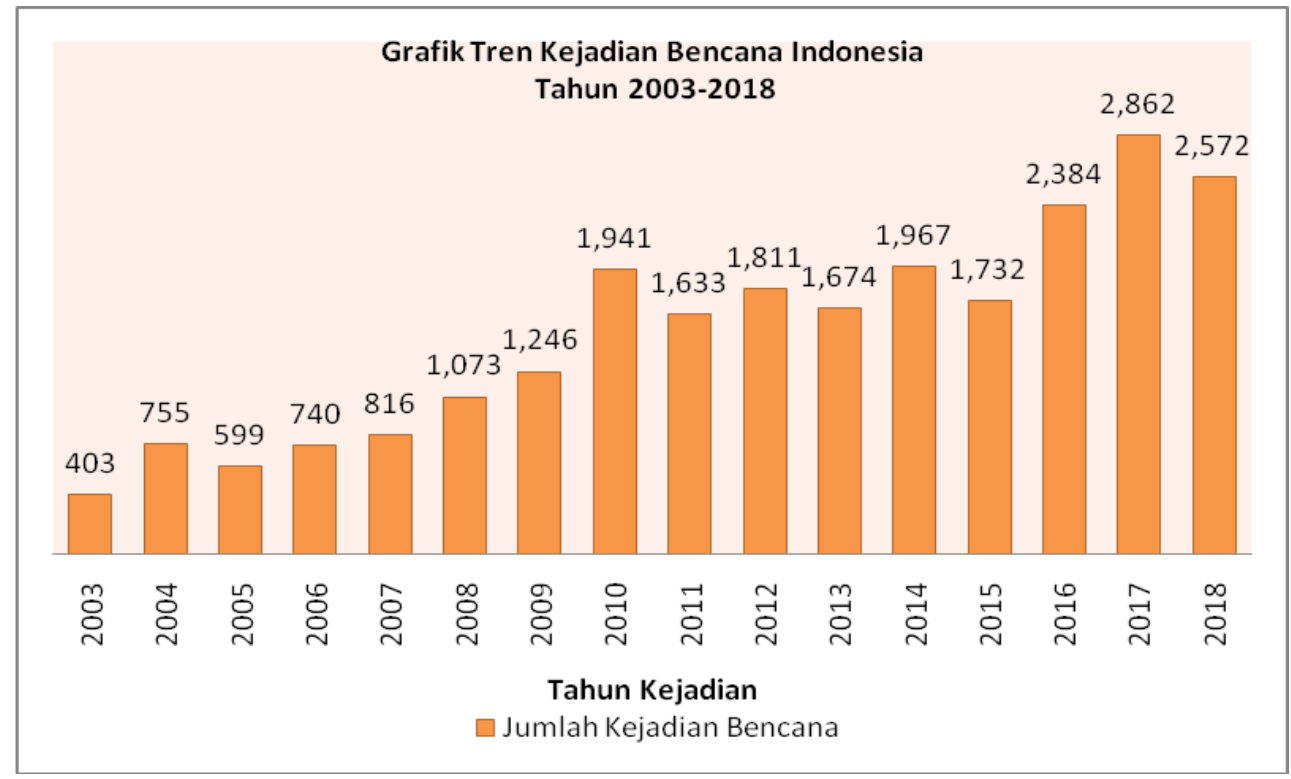

Gambar 1. Grafik Tren Kejadian Bencana Hidrometeorologi di Indonesia. Sumber: BNPB, 2018

Ancaman atau bahaya bencana yang melanda Provinsi Jawa Tengah meliputi bencana banjir, banjir bandang, cuaca ekstrim, epidemi dan wabah penyakit, gelombang ekstrim dan abrasi, gempa bumi, tsunami, kebakaran hutan dan lahan, kegagalan teknologi, kekeringan, dan letusan gunung api (BNPB, 2015). Adanya berbagai ancaman bencana tersebut menyebabkan Provinsi Jawa Tengah memiliki indeks risiko bencana multi bahaya yang tinggi yaitu 146.47 (Nugraho et al., 2018). Menurut data BNPB mulai Tahun 20132018, tren kejadian bencana hidrometeorologi

mengalami peningkatan terus menerus hingga puncaknya pada Tahun 2017. Pada tahun 2018 tercatat 2.572 kejadian bencana hidrometeorologi di Indonesia yaitu banjir, tanah longsor, dan angin puting beliung.

Indeks risiko bencana multi bahaya yang tinggi juga dimiliki salah satu kabupaten di Provinsi Jawa Tengah yaitu Kabupaten Pati, dengan nilai 174.00 pada Tahun 2018 (Nugraho et al., 2018). Kabupaten Pati terletak di sekitar dataran rendah dan pesisir yang meliputi wilayah Kecamatan Juwana, 
Trangkil, Trayu, Pati, Margorejo, Wedarijaksa, Batangan, Dukuhseti, Jakenan, Sukolilo, Kayen dan Kecamatan Gabus (Bappeda, 2019). Wilayah yang menjadi fokus penelitian ini adalah Kecamatan Gabus atau lebih khususnya di Desa Banjarsari, disebabkan desa tersebut termasuk desa yang mengalami banjir cukup parah karena dekat dengan Sungai Silunggo atau Juwana. Banjir yang terjadi di beberapa titik di Desa Banjarsari mengakibatkan kerugian mencapai ratusan juta rupiah (Adinanta et al., 2017).

Melihat kondisi Desa Banjarsari yang sering mengalami bencana banjir dan menyebabkan kerugian cukup besar maka diperlukan adanya identifikasi mengenai tingkat pengetahuan dan kesiapsiagaan masyarakat yang ada di Desa Banjarsari Kecamatan Gabus Kabupaten Pati guna untuk mengurangi risiko bencana. Berdasarkan latar belakang tersebut maka penelitian ini memiliki tujuan untuk mengetahui tingkat pengetahuan masyarakat tentang bencana banjir di Desa Banjarsari Kecamatan Gabus dan mengidentifikasi tingkat kesiapsiagaan masyarakat tentang bencana banjir di Desa Banjarsari Kecamatan Gabus.

\section{B. METODE}

Penelitian ini termasuk dalam penelitian deskriptif kuantitatif dengan berdasar pada variabel yang diteliti.
Teknik pengumpulan data primer yang digunakan dalam penelitian ini adalah metode observasi, pengisian kuisoner, dan dokumentasi. Data primer dalam penelitian ini berkaitan dengan data pengetahuan dan kesiapsiagaan masyarakat Desa Banjarsari tentang bencana banjir. Adapun data sekundernya meliputi data monografi Desa Banjarsari Kecamatan Gabus dan data-data jurnal yang berkaitan dengan kesiapsiagaan masyarakat tentang bencana banjir.

Teknik pengambilan sampel pada penelitian ini menggunakan metode probability sampling dengan pendekatan teknik simple random sampling. Teknik simple random sampling merupakan teknik sederhana (simple) yang mana pengambilan sampelnya dilakukan secara acak tanpa memperhatikan strata dalam populasi (Sugiyono, 2013). Sampel yang diambil dalam penelitian ini adalah $270 \mathrm{KK}$ dengan populasi berjumlah $824 \mathrm{KK}$ dari 1 dusun/dukuh di Desa Banjarsari, Kecamatan Gabus berdasarkan taraf signifikansi $5 \%$. Penentuan besar sampel dapat menggunakan rumus berikut.

$$
\mathrm{n}=\frac{N}{1+N\left(d^{2}\right)}
$$

(Notoatmodjo, 2010)

Keterangan:

$$
\begin{array}{ll}
\mathrm{n} & =\text { Besar sampel } \\
\mathrm{N} & =\text { Besar populasi } \\
\mathrm{d} & =\text { Tingkat kepercayaan }
\end{array}
$$


Berdasarkan rumus tersebut, diperoleh besar sampel yaitu $270 \mathrm{KK}$. Selanjutnya pengambilan sampel dilakukan secara random sampling dengan menggunakan randomisasi yaitu membuat nama atau nomor $\mathrm{KK}$ dalam software Microsoft Excel esuai dengan jumlah KK dari Dusun tersebut. Kemudian mengacak nama warga desa secara random sesuai dengan jumlah sampel dari 1 dusun, setelah itu nama atau nomor KK tersebut dapat dijadikan sebagai sampel responden.

Kemudian teknik analisis data dilakukan dengan metode scoring atau penilaian untuk mengetahui tingkat kesiapsiagaan masyarakat terhadap bencana banjir, dengan perhitungan menggunakan rumus sebagai berikut.

$\mathrm{IKB}=35(\mathrm{PS})+10(\mathrm{~K})+15(\mathrm{RTD})+$ $25(\mathrm{SPB})+15(\mathrm{MS})$

Keterangan:

IKB : Indeks Kesiapsiagaan Bencana

PB : Pengetahuan dan Sikap

K : Kebijakan

RTD : Rencana Tanggap Darurat

SPB : Sistem Peringatan Bencana

MS : Mobilitas Sumberdaya

Adapun rumus deskriptif persentase sebagai berikut:

$$
\mathrm{DP}=\frac{n}{N} \times 100 \%
$$

Keterangan:

DP= Deskriptif Persentase (\%)

$\mathrm{n}=$ Skor empirik (Skor yang diperoleh)
$\mathrm{N}=$ Skor ideal untuk setiap item pertanyaan.

\section{HASIL DAN PEMBAHASAN \\ C.1. Hasil}

Data mengenai pengetahuan dan kesiapsiagaan masyarakat tentang bencana banjir di Dusun Biteng, Desa Banjarsari diolah menggunakan analisis statistik deskriptif. Pengambilan data dalam penelitian ini menggunakan kuesioner yang terdiri dari 270 responden dari 824 Kepala Keluarga dimana dari 270 responden terdiri dari $3 \%$ responden dengan tingkat Pendidikan terakhir SD, 4\% dengan tingkat Pendidikan terakhir SMP, 84\% dengan tingkat Pendidikan terakhir SLTA, dan 7\% dengan tingkar terakhir S1/S2. Selain itu 270 responden dengan masing-masing tingkat pendidikan terakhir terdiri dari 22,6\% responden dengan rentang usia 20-40 tahun, 38,5\% responden dengan rentang usia 41-51 tahun, dan 38,9\% responden dengan rentang usia 52-62 tahun. Kuesioner terdiri 5 parameter yaitu pengetahuan, kebijakan, rencana tanggap darurat, sistem peringatan bencana, dan mobilisasi sumberdaya.

1. Pengetahuan

Parameter tingkat pengetahuan dalam penelitian ini diperoleh dari penyebaran kuesioner kepada 270 responden dengan jumlah 10 item pertanyaan. Adapun skor maksimal yang 
mungkin dicapai adalah 10 dan skor minimal adalah 0 .

Baris skor pengetahuan menunjukkan hasil jawaban "Ya" dari 270 responden atas 10 item pertanyaan. Skor yang sering dicapai oleh responden adalah 10 dengan jumlah responden yang menjawab sebanyak 186 orang atau 68,9\% dari 270 responden, sedangkan skor minimalnya yaitu 4 dan 5 dengan jumlah responden sebanyak 2 orang.

Tingkat pengetahuan masyarakat

Desa Banjarsari $98,5 \%$ dari 270 responden memiliki tingkat pengetahuan tinggi dan 1,5\% dari 270 responden memiliki tingkat pengetahuan sedang. Hal tersebut menunjukkan bahwa masyarakat Desa Banjarsari telah mampu memahami karakteristik bencana banjir dan penanggulangan bencananya.

\section{Kebijakan}

Parameter kebijakan diperoleh dari penyebaran kuesioner yang terdiri dari 3 item pertanyaan kepada 270 responden. Adapun skor maksimal yang mungkin dicapai adalah 3 dan skor minimal adalah 0 .

Skor yang sering dicapai oleh responden adalah 3 dengan jumlah responden yang menjawab sebanyak 258 orang atau 95,6\% dari 270 responden, sedangkan skor minimalnya yaitu 1 dengan jumlah responden sebanyak 1 orang. Terkait dengan tingkat pemahaman kebijakan, 95,6\% dari 270 responden masyarakat Desa Banjarsari memiliki tingkat pemahaman kebijakan dan panduan tinggi, 4,6\% dari 270 responden memiliki tingkat pemahaman kebijakan dan panduan sedang, dan 0,4\% dari 270 responden memiliki tingkat pemahaman kebijakan dan panduan rendah. Hal tersebut menunjukkan bahwa masyarakat Desa Banjarsari telah mengetahui kebijakan dan panduan tentang bencana banjir.

3. Rencana Tanggap Darurat

Parameter rencana tanggap darurat dalam penelitian ini diperoleh dari penyebaran kuesioner yang terdiri dari 9 item pertanyaan kepada 270 responden. Rencana tanggap darurat terkait mengenai evakuasi dan penyelamatan agar dapat meminimalkan korban jiwa (Firmansyah et al., 2014). Adapun skor maksimal yang mungkin dicapai adalah 9 dan skor minimal adalah 0 .

Skor yang sering dicapai oleh responden adalah 9 dengan jumlah responden yang menjawab sebanyak 230 orang atau $85,2 \%$ dari 270 responden, sedangkan skor minimalnya yaitu 2 dengan jumlah responden sebanyak 1 orang. Sebanyak $94,1 \%$ dari 270 responden memiliki tingkat pemahaman rencana tanggap darurat tinggi, 5,5\% dari 270 responden memiliki tingkat pemahaman rencana tanggap darurat sedang, dan 1,5\% dari 270 responden memiliki tingkat pemahaman rencana 
tanggap darurat rendah. Hal tersebut menunjukkan bahwa masyarakat Desa Banjarsari telah memiliki rencana tanggap darurat bencana banjir yang baik.

\section{Sistem Peringatan Dini}

Menurut Dodon (2013) dalam (Sari \& Husna, 2017) sistem peringatan dini dalam menghadapi bencana meliputi tanda peringatan dan penyebaran informasi saat terjadinya bencana. Parameter sistem peringatan dini dalam penelitian ini diperoleh dari penyebaran kuesioner yang terdiri dari 4 item pertanyaan kepada 270 responden. Adapun skor maksimal yang mungkin dicapai adalah 4 dan skor minimal adalah 0 .

Skor yang sering dicapai oleh responden adalah 4 dengan jumlah responden yang menjawab sebanyak 231 orang $(85,6 \%)$ dari 270 responden, sedangkan skor minimalnya yaitu 2 dengan jumlah responden sebanyak 7 orang. Sebanyak 97,4\% dari 270 responden memiliki tingkat pemahaman sistem peringatan dini tinggi, dan 2,6\% dari 270 responden memiliki tingkat pemahaman sedang. Hal tersebut menunjukkan bahwa masyarakat Desa Banjarsari telah memiliki sistem peringatan dini bencana banjir yang baik.

5. Mobilisasi Sumber Daya Parameter rencana tanggap darurat diperoleh dari penyebaran kuesioner yang terdiri dari 8 item pertanyaan kepada 270 responden. Adapun skor maksimal yang mungkin dicapai adalah 4 dan skor minimal adalah 0 .

Skor yang sering dicapai oleh responden adalah 4 dengan jumlah responden yang menjawab sebanyak 202 orang atau $74,8 \%$ dari 270 responden, sedangkan skor minimalnya yaitu 2 dengan jumlah responden sebanyak 7 orang.

Sebanyak $94,8 \%$ dari 270 responden memiliki tingkat mobilisasi sumber daya tinggi yang meliputi kegiatan pelatihan kesiapsiagaan bencana banjir, dimana masyarakat diberikan sosialisasi serta simulasi mengenai kesiapsiagaan bencana banjir sebagai upaya dalam rangka mengamankan aset dan investasi yang dimiliki masyarakat. Dalam upaya ini masyarakat dapat menyiapkan tabungan, investasi maupun asuransi sebagai kesiapsiagaan dalam menghadapi bencana banjir. $4,8 \%$ dari 270 responden memiliki tingkat mobilisasi sumber daya sedang dan $0,4 \%$ dari 270 responden memiliki tingkat mobilisasi sumber daya rendah. Hal tersebut menunjukkan bahwa masyarakat Desa Banjarsari telah memiliki mobilisasi sumberdaya terhadap bencana banjir yang sangat baik. 
6. Tingkat Kesiapsiagaan Masyarakat

Kesiapsiagaan masyarakat dapat dihitung dengan menggabungkan parameter pengetahuan, kebijakan, rencana tanggap darurat, sistem peringatan dini, dan mobilisasi sumberdaya. Adapun rumus indeks kesiapsiagaan masyarakat adalah sebagai berikut.

Indeks kesiapsiagaan $=35(\mathrm{PS})+10(\mathrm{~K})$

$+15(\mathrm{RTD})+25(\mathrm{SPB})+15(\mathrm{MS})$.

$=35(10)+10(3)+15(9)+25(4)+15(8)$

$=735$ (Skor maksimal)

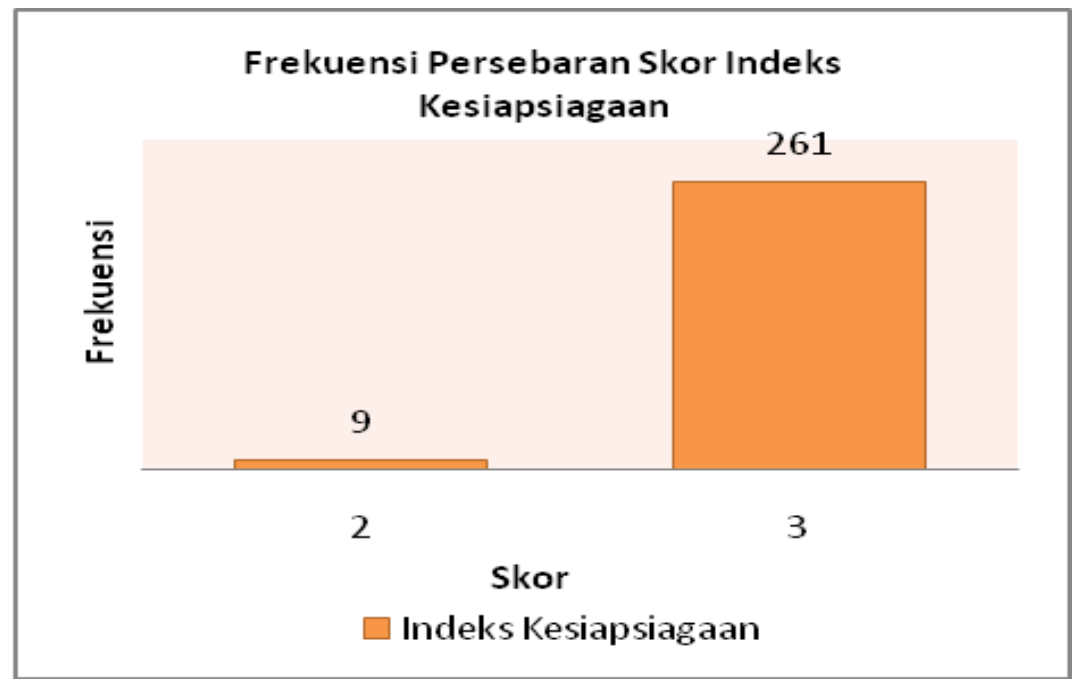

Gambar 2. Prosentase Indeks Kesiapsiagaan. Sumber: hasil perhitungan, 2020

Gambar 2 menunjukkan prosentase indeks kesiapsiagaan responden yang mencapai skor maksimal ada sebanyak 261 orang atau 96,7\%. Berdasar hal tersebut dapat disimpulkan bahwa tingkat kesiapsiagaan masyarakat Desa Banjarsari termasuk dalam kategori siap. Hal tersebut dikarenakan kemampuan masyarakat Desa Banjarsari menghadapi bencana banjir sudah baik karena telah mengenali potensi dan tanda-tanda terjadinya banjir dan membuang sampah pada tempat sampah. Kemudian adanya sosialisasi dan simulasi tentang bencana banjir yang diselenggarakan oleh pemerintah Desa Banjarsari telah meningkatkan pemahaman dan pengetahuan masyarakat Desa Banjarsari dalam penanggulangan bencana banjir pada tahap pra bencana, saat darurat bencana, dan pasca bencana. Di samping itu, adanya sosialisasi dan simulasi telah merubah sikap masyarakat Desa Banjarsari menjadi lebih sigap dan tanggap bencana banjir.

7. Persebaran Area Terendam Banjir

Gambar 3 menjelaskan tentang persebaran spasial area yang terendam dan tidak terendam banjir. Sebagian besar rumah yang terendam banjir berada di dekat Sungai Silugonggo atau Juwana. 


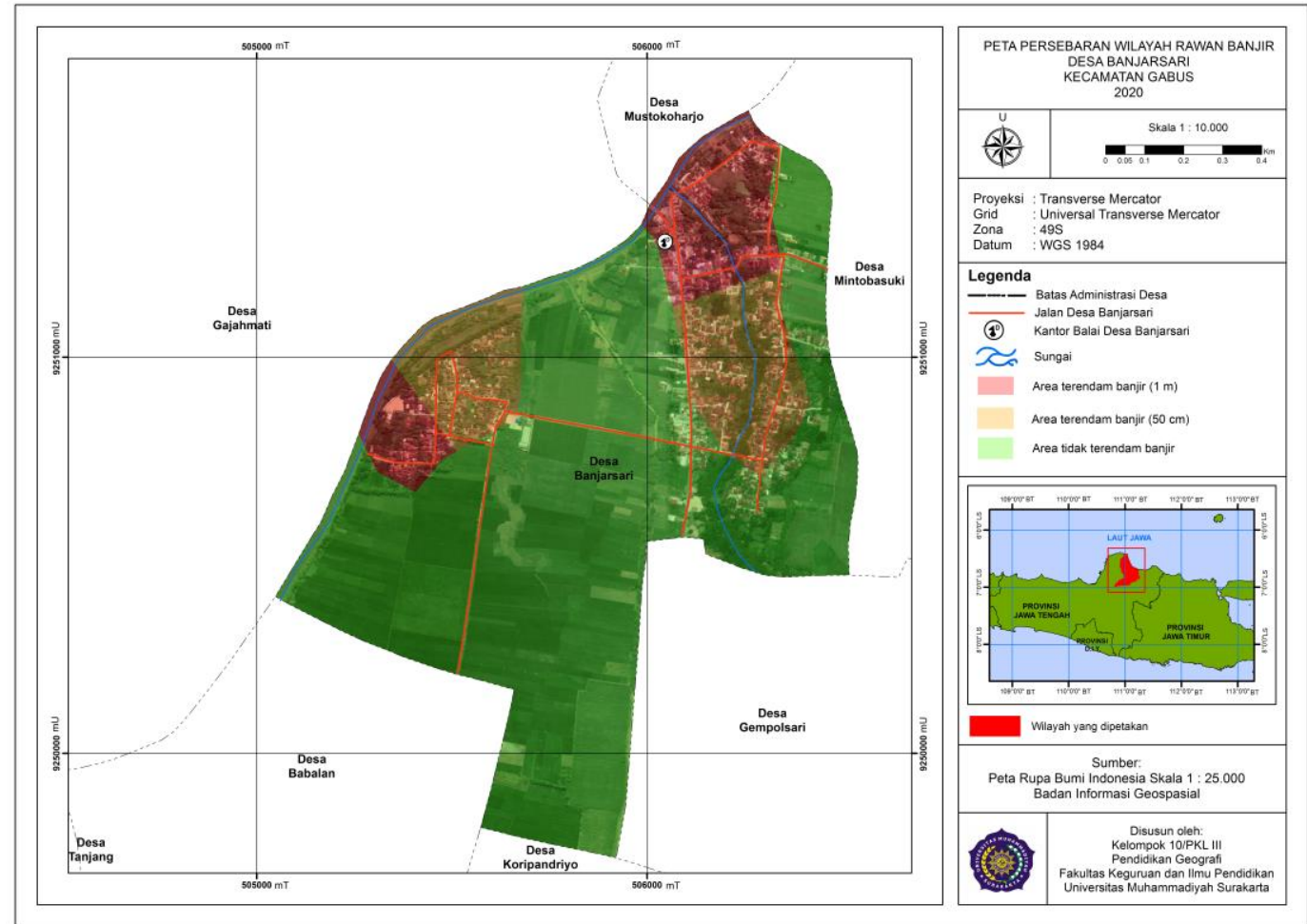

Gambar 3. Area yang terendam dan tidak terendam banjir. Sumber: Hasil pengolahan data , 2020

Biasanya banjir merendam rumah masyarakat setinggi $50 \mathrm{~cm}$ hingga $1 \mathrm{~m}$.

Bencana banjir setinggi $50 \mathrm{~cm}$ merendam wilayah Desa Banjarsari ditunjukkan oleh warna orange dengan luas totalnya yaitu $159.4278 \mathrm{~m}^{2}$. Kemudian banjir setinggi 1 meter merendam wilayah Desa Banjarsari ditunjukkan oleh warna merah muda dengan luas totalnya yaitu $206.041 \mathrm{~m}^{2}$. Adapun luas area yang tidak terendam banjir ditunjukkan oleh warna hijau mudadengan luas $1.028 .159 \mathrm{~m}^{2}$. Masyarakat yang tinggal di dekat sungai mayoritas bermata pencaharian sebagai petani sehingga mereka terdampak langsung bencana banjir yang cukup besar. Meskipun demikian, kesiapsiagaan masyarakatnya sangat baik karena mereka lebih menggunakan kearifan lokal dalam menghadapi bencana banjir, yaitu mempersiapkan perahu saat bencana banjir tiba.

Berbeda halnya dengan rumah yang tidak terendam banjir dikarenakan letaknya jauh dari bantaran Sungai Silugonggo, namun kesiapsiagaan masyarakatnya juga sangat baik. Hal tersebut dibuktikan dengan adanya upaya-upaya yang dilakukan masyarakat yaitu tersedianya peta jalur evakuasi, tempat pengungsian, adanya bangunan rumah panggung dan pelaksanaan simulasi serta pelatihan kesiapsiagaan menghadapi banjir di Desa Banjarsari. Selain itu, adanya 
sistem peringatan dini lokal berupa kentongan dan penyebaran informasi menggunakan alat elektronik misal handphone dapat meminimalkan dampak bencana banjir yang terjadi di Desa Banjarsari, Kecamatan Gabus.

\section{C.2. Pembahasan}

Tingkat pengetahuan masyarakat Desa Banjarsari tergolong tinggi yaitu sebanyak 98,5\% dari 270 responden berpengetahuan tinggi terhadap bencana banjir. Masyarakat Desa Banjarsari memiliki tingkat pengetahuan tinggi karena mereka telah mengetahui dan memahami tentang karakteristik bencana banjir serta cara menanggulanginya. Hasil penelitian ini sejalan dengan penelitian Sari dan Husna (2017) yang menunjukkan bahwa pengetahuan masyarakat mengenai kesiapsiagaan bencana dilihat dari pemahaman masyarakat mengenai karakter bencana banjir yang ada di sekitarnya, latar belakang budaya, dan tingkat pemahaman masyarakat aman dalam menerima informasi. Pengetahuan dan sikap yang dimiliki masyarakat juga dapat diperoleh dari pengalaman kejadian bencana banjir di hampir tiap tahunnya, sehingga akan mempengaruhi kepedulian masyarakat untuk lebih meningkatkan sikap siap siaga banjir (Erlia et al., 2017).

Kemudian rencana tanggap darurat yang dimiliki oleh masyarakat Desa Banjarsari sudah baik, ditunjukkan dengan bukti bahwa terdapat peta atau jalur evakuasi banjir di Desa Banjarsari, adanya tempat pengungsian sementara, tersedia alat penerangan saat kondisi darurat bencana banjir dan tersedianya perlengkapan obat-obatan/P3K. Hasil penelitian ini didukung oleh penelitian Sari dan Husna (2017) yang menunjukkan bahwa masyarakat memiliki rencana tanggap darurat bencana yang baik karena seringnya mengalami bencana banjir menjadikan masyarakat lebih siap dan tanggap terhadap bencana banjir, seperti menyediakan tempat pengungsian sementara, mempersiapkan perlengkapan obat-obatan, tali, pelampung air bersih ditempat pengungsian, serta mengungsi ke tempat yang lebih tinggi ketika terjadi banjir. Rencana tanggap darurat perlu dibuat dan ditetapkan anggota masyarakat maupun anggota keluarga sebelum terjadi bencana banjir agar tercipta kesepakatan bersama dalam tanggap darurat banjir (Akhirianto, 2018).

Masyarakat Desa Banjarsari juga memiliki sistem peringatan dini dan mobilisasi sumber daya yang baik. Sistem peringatan dini yang digunakan masyarakat Desa Banjarsari dalam menghadapi banjir yaitu masyarakat telah mempersiapkan kentongan, sirine, dan media komunikasi seperti WhatsApp sebagai sumber informasi bencana. Hasil penelitian ini sama dengan 
penelitian Akhirianto (2018) yang menunjukkan bahwa sistem peringatan bencana banjir yang dimiliki oleh masyarakat di wilayah Pondok Gede Permai cukup baik. Sistem peringatan dini di wilayah tersebut sangat mengandalkan informasi bencana banjir dari komunitas Cileungsi Cikeas dan kompi 887. Kedua komunitas tersebut menginformasikan kepada masyarakat mengenai ketinggian muka air banjir dan kondisi cuaca melalui media WhatsApp dan telegram.

Mobilisasi

sumberdaya merupakan kemampuan individu untuk memobilisasi sumberdaya yang tersedia yaitu berupa Sumber Daya Manusia (SDM) dan pendanaan serta saranaprasarana yang vital (Hidayati, 2008). Mobilisasi sumber daya yang dimiliki masyarakat Desa Banjarsari ditunjukkan dengan adanya partisipasi masyarakat dalam seminar, simulasi dan pelatihan kesiapsiagaan bencana sehingga keterampilan menghadapi bencana banjir menjadi meningkat. Di samping itu masyarakat telah mempersiapkan tabungan dan investasi dalam rangka menghadapi bencana banjir.

Berdasarkan kelima parameter tersebut menujukkan bahwa tingkat kesiapsiagaan bencana banjir yang dimiliki masyarakat Desa Banjarsari tergolong siap. Pengklasifikasian kategori siap tersebut dibuktikan dengan adanya upaya-upaya yang dilakukan masyarakat dalam penanggulangan bencana banjir secara aktif dan berkelanjutan. Hasil penelitian mengenai tingkat kesiapsiagaan bencana banjir ini berbanding terbalik dengan penelitian Saifuddin et al. (2015) yang menunjukkan bahwa masyarakat Kecamatan Meureubo memiliki tingkat kesiapsiagaan bencana banjir kurang siap karena masih rendahnya partisipasi masyarakat dalam menghadapi banjir, dimana setiap orang belum menyiapkan perencanaan keluarga dalam menghadapi bencana. Selain itu, kurangnya kesadaran dan keaktifan masyarakat dalam mengikuti pelatihan dan simulasi tentang bencana banjir akan membuat masyarakat menjadi sangat rentan.

\section{KESIMPULAN}

Berdasarkan hasil analisis dan pembahasan maka dapat disimpulkan bahwa tingkat pengetahuan masyarakat Desa Banjarsari tergolong tinggi karena sebagian besar masyarakat telah memahami dan mengetahui tentang apa itu bencana banjir dan cara penanggulangannya dilihat dari banyaknya responden yang memiliki tingkat pendidikan SLTA dan perguruan tinggi. Adapun tingkat kesiapsiagaan masyarakat Desa Banjarsari menjadi tinggi karena harus berhadapan dengan kondisi Desa yang sering mengalami bencana banjir setiap tahunnya. Kesiapsiagaan masyarakat dapat 
meningkat melalui upaya-upaya pengurangan risiko bencana banjir. Meskipun tingkat pengetahuan dan kesiapsiagaan masyarakat berkategori tinggi, namun perlu adanya penguatan simulasi dan pelatihan kesiapsiagaan bencana banjir secara teratur bersama stakeholder terkait guna meminimalkan dampak bencana banjir.

\section{DAFTAR PUSTAKA}

Adinanta, I., Hakim, M. L., \& Utamaningsih,

A. (2017). ANALISIS TATA KELOLA DESA TANGGUH BENCANA DALAM PERSPEKTIF PENGURANGAN RISIKO BENCANA (Studi Di Desa Banjarsari Kecamatan Gabus Kabupaten Pati). Jurnal Mahasiswa Ilmu Pemerintahan, 03(1), 1-12.

Akhirianto, N.

A

(2018).

PENGETAHUAN

DAN

KESIAPSIAGAAN

MASYARAKAT TERHADAP

BENCANA BANJIR DI KOTA

BEKASI (STUDI KASUS:

PERUMAHAN PONDOK GEDE PERMAI). Jurnal Alami, 2(1), 10.

Amri, Mohd. R., Yulianti, G., Yunus, R., Wiguna, S., Adi, A. W., Ichwana, A. N., Randongkir, R. E., \& Septian, R. T. (2016). Risiko Bencana Indonesia (R. Jati \& Mohd. R. Amri, Eds.). Badan Penanggulangan Bencana Nasional.
Bappeda. (2019). Penyusunan Revisi Rencana Program Investasu Jangka Menengah (RPIJM). Badan Perencanaan Pembangunan Daerah Pemerintah Kabupaten Pati.

BNPB. (2015). Dokumen Kajian Risiko Bencana Jawa Tengah 20162020 .

BNPB. (2019). Jurnal Dialog Penanggulangan Bencana (Vol. 10, Issue 1, pp. 1-104). Pusat Data Informasi dan Humas Badan Nasional Penanggulangan Bencana. Erlia, D., Kumalawati, R., \& Aristin, N.

F. (2017).

ANALISIS KESIAPSIAGAAN

MASYARAKAT DAN PEMERINTAH MENGHADAPI BENCANA BANJIR DI KECAMATAN MARTAPURA BARAT KABUPATEN BANJAR. Jurnal Pendidikan Geografi, 4(3), 15-24.

Firmansyah, I., Rasni, H., Studi, P., Keperawatan, I., \& Jember, U. (2014). Hubungan Pengetahuan dengan Perilaku Kesiapsiagaan dalam Menghadapi Bencana Banjir dan Longsor pada Remaja Usia 1518 tahun di SMA Al-Hasan Kemiri Kecamatan Panti Kabupaten Jember (The Correlation Between Knowledge and behavior preparedness in Facing of. 
https://repository.unej.ac.id/handle/ $123456789 / 6065$

Hidayati, D. (2008). KESIAPSIAGAAN MASYARAKAT: PARADIGMA

BARU PENGELOLAAN

BENCANA ALAM DI INDONESIA. Jurnal

Kependudukan Indonesia, III(1), 69-84.

https://doi.org/10.14203/jki.v3i1.16

4

Nugraho, P. C., Pinuji, S. E., Ichwana, A. N., Nugraha, A., Wiguna, S., Syauqi, Randongkir, R. E., Shabrina, F. Z., Septian, R. T., Iriansyah, A. A., Hafiz, A., Hamzah, A., Seniarwan, \& Setiawan, A. (2018). Indeks Risiko Bencana Indonesia (IRBI) (R. Yunus \& P. C. Nugroho, Eds.). Direktorat Pengurangan Risiko Bencana Badan Nasional Penanggulangan Bencana.

Saifuddin, Indra, \& Hermansyah. (2015). ANALISIS TINGKAT KESIAPSIAGAAN

MASYARAKAT DALAM
MENGHADAPI BENCANA BANJIR DI KECAMATAN MEUREBO KABUPATEN ACEH BARAT. Jurnal Ilmu Kebencanaan (JIKA) Pascasarjana Universitas Syiah Kuala, 2(1). 51-57.

Sari, D. I., \& Husna, C. (2017). Kesiapsiagaan Bencana Banjir Pada
Masyarakat Daerah Risiko Tinggi Dan Risiko Rendah Banjir. Jurnal Ilmiah Mahasiswa Fakultas Keperawatan, 2(3), 1-9.

Sugiyono. (2013). Metode Penelitian Kuantitatif, Kualitatif, dan Tindakan (19th ed.). ALFABETA, CV. 